\title{
Solitary fibrous tumor of the kidney: a case report
}

\author{
Tumor fibroso solitário renal: relato de caso clínico
}

\author{
Gustavo Soares Corrêa Silva ${ }^{1}$; Maurício Buzelin Nunes²; Pedro Bastos Guimarães de Almeida ${ }^{3}$; Rafael Morroni de Oliveira3; \\ Risia Edwiges de Oliveira Guimarães ${ }^{4}$; Victor Satler Pylro ${ }^{5}$
}

\begin{abstract}
We describe a case report of a rare cancer affecting the kidney of 63 years of age patient who underwent imaging studies from ultrasound, computed tomography, and magnetic resonance imaging, due to complaints: left back pain and urinary obstruction. Sonographic and radiological features of the mass found suggested the diagnosis of a malignant tumor of parenchymal origin. The pathological and immunohistochemical studies of the resected anatomical specimen, however, diagnosed a rare benign variant of solitary fibrous tumor originating in the inferior pole of the left kidney.
\end{abstract}

Key words: hemangiopericytoma; solitary fibrous tumor; kidney.

\section{INTRODUCTION}

The fibrous tumor was first described in 1942 by Stout and Murray $^{(9)}$ as a likely benign neoplasm of mesothelial origin, but of uncertain biological behavior, i.e., having a rare malignant variant. The solitary fibrous tumors (SFT) are neoplasms that often exhibit a hemangiopericytoma-like vascular arrangement pattern and pleura is the main primary site. About $30 \%$ of diagnosed cases are found in soft tissue and parenchymal organs. There are few cases described of kidney involvement by this tumor. Imaging tests methods currently used, only suggest the possibility of malignancy of the tumor, therefore the macroscopic, histological and immunohistochemical analyzes of the lesion are crucial. Due to scarcity of the topic in the literature, there is still no consensus on the follow up of patients after surgical treatment.

The kidney involvement by this tumor is very rare, and there are no imaging features capable to define the potential of benignity or malignancy of this neoplasm. Due to its doubtful clinical behavior, we can mention the benign variant of the tumor to an aggressive metastatic malignancy neoplasm; therefore it is always recommended the surgical routine treatment.

\section{CLINICAL CASE REPORT}

Patient J. S. F, 63 years of age, retired, was admitted to the Hospital Santa Casa de Misericórdia de Belo Horizonte-MG with progressive dysphagia to solid food and pain of moderate intensity in the left lumbar region for six months. He denied weight loss, fever, or night sweats. He complained of urinary changes suggestive of bladder outlet obstruction due to symptoms such as weak urinary stream, intermittence, and nocturia. His previous morbid history presented systemic arterial hypertension controlled with Losartan administration of $50 \mathrm{mg} / 12$ hours. He was alert, hydrated, flushed, nonicteric, and acyanotic on clinical examination. On auscultation, the cardiovascular and respiratory systems examined had normal and rhythmic sounds with two normal clicks without murmurs, peripheral pulses were strong and palpable. Blood pressure measurement was $130 \times 80 \mathrm{mmHg}$. Heart rate was 85 bpm, physiological vesicular murmur without adventitious sounds, eupnoea. During examination, abdomen was painful on deep palpation of the left flank, with no evidence of masses. During digital rectal examination, prostate showed about 60 grams of weigh, with fibroelastic consistency and no palpable nodules.

First submission on 20/01/14; last submission on 27/03/14; accepted for publication on 09/05/14; published on 20/08/14

1. Resident of Anatomic Pathology-Hospital Santa Casa de Misericórdia de Belo Horizonte.

2. Physician preceptor of Department of Anatomic Pathology-Hospital Santa Casa de Misericórdia de Belo Horizonte.

3. Physician specializing in Urology at Urology Service-Hospital Santa Casa de Misericórdia de Belo Horizonte.

4. Medical student-Faculdade de Ciências Médicas de Minas Gerais.

5. PhD in Microbiology-Argonne National Laboratory, USA. 
Laboratory tests showed abnormal elements and sediments showing microscopic hematuria. Esophagus, stomach, and duodenum contrast radiographs revealed megaesophagus group III de Rezende. Renal and urinary tract ultrasound described the presence of a complex renal mass in the topography of the left kidney, light ureterohydronephrosis in the left, and moderate in the right. The bladder wall thickness was increased.

Abdominal and pelvic CT scan showed a bulky renal mass, apparently related to the left lower pole of the kidney, with intermediate density, showing hypodense points suggestive of necrosis, as well as internal calcifications (Figure 1).

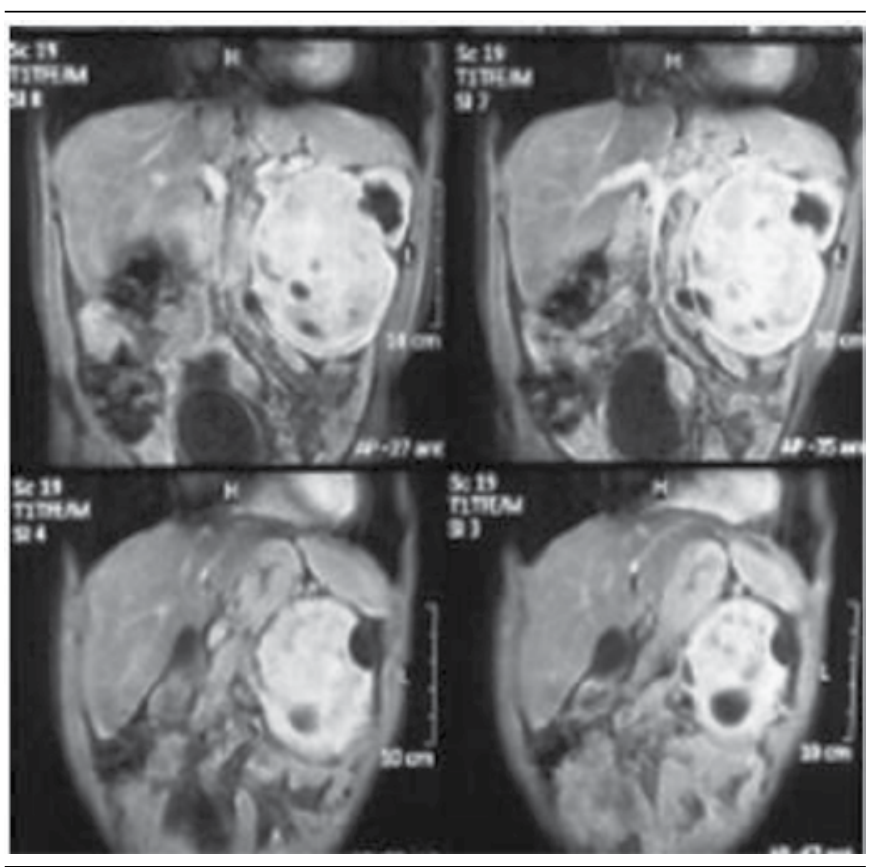

FIGURE 1 -Computer tomography of abdomen showing large mass in the left kidney

The hypothesis of a malignant renal neoplasm was questioned, and based on this conjecture we choose to perform radical left nephrectomy by subcostal approach and lymphadenoctomy. The surgery occurred without complications.

A block surgical specimen was sent to the anatomic pathologic laboratory at Hospital Santa Casa de Misericórdia de Belo Horizonte-MG.

At macroscopic examination, the surgical specimen was represented by the left kidney and perirenal fat measuring $18 \mathrm{~cm}$ long, $14 \mathrm{~cm}$ de high, $9 \mathrm{~cm}$ wide, and 1,350 g weigh. The piece had smooth and bosselated with multiple nodular projections outer surface. The cut sections identified a tumor mass brownreddish colored with firm consistency, measuring $16 \mathrm{~cm}$ long and $1,2 \mathrm{~cm}$ de wide, extending throughout the renal parenchyma. The microscopic examination of histological sections using routine staining (hematoxylin and eosin [H\&E]) showed neoplasm characterized by proliferation of slightly elongated, fusiform, and ovoid cells, without atypia, with inconspicuous nuclei producing solid masses within fibrous stroma with interspersed collagen deposition (Figure 2). Tortuous ectatic vessels, sometimes similar to hemangiopericytoma arrangements, were observed. Occasional mitotic figures are seen (less than three mitoses per 10 high power fields) (Figure 3). Hilar vessels, ureters, and isolated lymph nodes were not affected by the cancer.

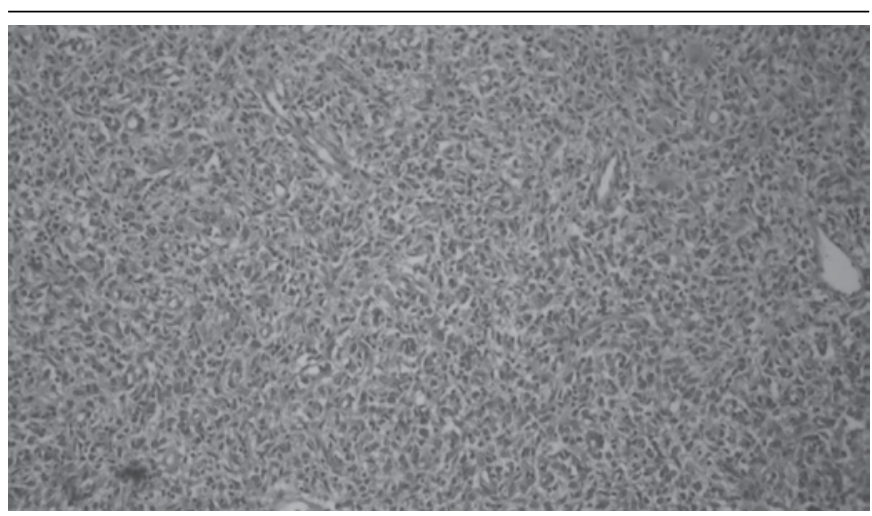

FIGURE 2 - Histological sections studied in routine staining (HEE) showed a spindle cells proliferation surrounded by a fibrous and collagen stroma in between pattern. Hemangiopericytoma-like vascular arrangements are observed HEE: hematoxylin and eosin.

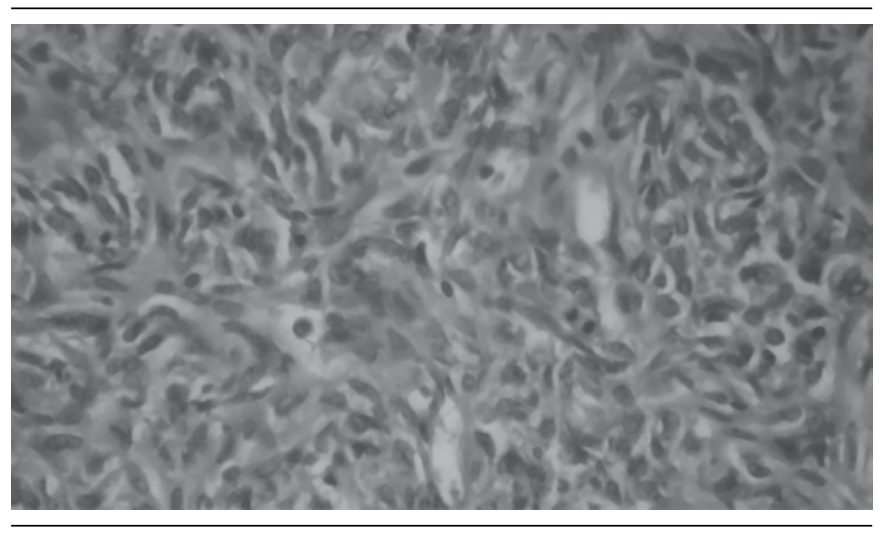

FIGURE 3 - Sections studied in routine staining (HEE) showed loss of cytological architecture with stromal and perivascular hyalinization pattern. Collagen deposition can frequently be observed

HEE: hematoxylin and eosin.

Immunohistochemical study revealed negativity for smooth muscle actin, GP100 antigen, desmin, S-100 protein, and MDM2 IF2 protein; and focal expression for anti-CD 34 (hematopoetic cells and pericytes antigens). 
Postoperatively, the patient progressed to tubular acidosis type IV; he was discharged after clinical improvement and stabilization of the renal function.

\section{DISCUSSION}

The solitary fibrous tumor consists of an omnipresent entity of mesenchymal tumors of probable fibroblastic origin, which features prominent bundles in hemangiopericytoma-like vascular pattern. This neoplasm can be observed in middle-aged adults between 20 and 70 years of age (mean 50 years), no sex predilection. The solitary fibrous tumor can be found in any body location. In $40 \%$ of cases they are found in subcutaneous tissue; others are located in deep soft tissues of the extremities or extracompartimental in the head and neck region (especially in the orbit), chest wall, mediastinum, pericardium, retroperitoneum and abdnominal cavity region. Other locations, already described, include meninges, spinal cord, periosteum, salivary glands, lungs, thyroid, liver, gastrointestinal tract, adrenal glands, bladder, prostate and testicles ${ }^{(1,2,5,6,8,-11,13)}$.

Clinically, the patient complains of localized compressive pain. When it affects specific organs, especially the orbit, meninges, and the nasal cavity, the compressive symptomatology prevails in relation to others symptoms. Occasionally, large tumors may produce paraneoplastic syndromes that manifest with hypoglycemia due to insulin-like growth factor (IGF-1) production ${ }^{(3)}$.

Macroscopic analysis of solitary fibrous tumor shows welldefined and circumscribed masses, partially encapsulated, exhibiting a slow and painful growth, and measuring between 1 and $25 \mathrm{~cm}$ (average $5-8 \mathrm{~cm}$ ). In the cut sections they were grayish-white multinodular masses, with firm and elastic consistency. Tumors may be bulky with outer yellowish-brown and bocelated surface, when presenting adipocyte differentiation (lipomatous variant); myxoid or hemorrhagic changes are usually present $t^{(4,5,8,9,12)}$. Tumor necrosis and capsular invasion consist of aggressive and malignant criteria (10\% of cases) $)^{(4,5,12)}$.

Histopathological features of solitary fibrous tumor are presented with loss cellular architectural pattern, characterized by the combination of alternation of hypocellular and hypercellular areas separated by hyalinized fibrous bundles, with hemangiopericytoma-like vascular branches. Atypical tumors have fusiforms cells arrangements containing scanty cytoplasm and indistinct borders and chromatin dispersed in vesicular nuclei. Myxoid changes, areas of fibrosis and mast cells are commonly observed. Mitoses are sparse, rarely exceeding three mitoses per 10 high power fields. Some solitary fibrous tumors may contain mature unilocular fat tissue and/or multinucleated stromal giant cells overlapping with so-called lipomatous Hemangiopericytoma and giant cells angiofibroma. The malignant variant of solitary fobrous tumor is usually composed of hypercellular lesions showing, at least, focally moderate cytologic atypia, tumor necrosis, numerous mitoses (more than four mitoses per 10 high power fields), and capsular invasion ${ }^{(4,5,12)}$. Occasionally, there is an abrupt transition from benign solitary fibrous tumor into a highgrade sarcoma, representing a form of differentiation.

Immunohistochemical study has high relevance due to the huge range of differential diagnoses. The solitary fibrous tumor cells show reactivity to anti-CD34 (90\%-95\% of cases) $)^{(2,5,7-9,12)}$, and anti-CD99 (70\% of cases). About 20\% to 35\% of cases are variably positive for epithelial membrane antigen, B-cell lymphoma 2 (BCL-2), smooth muscle actin. It shows focal and limited reactivity for S-100 protein $^{(4,12)}$.

Prognostic factors depend on the variant of the tumor. Although most cases are benign, their biological behavior is still uncertain. About $10 \%$ to $15 \%$ behave aggressively; therefore, a strict follow-up of patients is required for a long period ${ }^{(4,5,12)}$. There is not a close correlation between the morphology and biological behavior, however, most histologically benign tumors do not metastasize and are non-recurrent. The retroperitoneal lesions are more aggressive than those in the extremities ${ }^{(4,5,12)}$. Metastases are more seen in the lungs, bones, and liver ${ }^{(12)}$.

\section{CONCLUSION}

Solitary fibrous tumor is an extremely rare neoplasm, as well as its location; few cases of the neoplasm in the renal fossa have been described according to the literature review. When this tumor affects the kidneys, symptoms depend on its volume, and are generally scarce and non-specific, represented by abdominal pain to deep palpation and microscopic hematuria, as in the case just described. Analyzes of imaging studies, such as ultrasound, computed tomography, and magnetic resonance imaging revealed the presence of a mass containing multiple nodules with associated areas of necrosis, leading to great difficulty of conclusion due to the differential diagnosis with renal malignancies. Histological features of the lesion are the proliferation of elongated, ovoid, and spindle cells, with alternating hypo and hypercellular areas divided by fibrous connective tissue plates. There is also vascular angle and prominence.

The differential diagnosis may include anything from benign lesions, such as leiomyoma, schwannoma, benign fibrous histiocytoma, to malignant lesions, such as low-grade fibromyxoid sarcoma and malignat peripheral tumor of tendon sheath; therefore immunohistochemical study for diagnostic investigation of the researched lesion is necessary. 


\section{RESUMO}

Descrevemos o relato de caso de uma rara neoplasia acometendo o rim de um paciente de 63 anos de idade que foi submetido a estudos de imagem por ultrassonografia, tomografia computadorizada e ressonância magnética nuclear devido às queixas apresentadas: dor lombar à esquerda e alterações miccionais sugestivas de obstrução infravesical. As características ultrassonográficas e radiológicas da massa encontrada sugeriam o diagnóstico de uma neoplasia maligna de origem parenquimatosa. 0 estudo anatomopatológico e imuno-bistoquímico da peça anatômica ressecada, entretanto, concluiu o quadro como variante benigna do raro tumor fibroso solitário originário do polo inferior do rim esquerdo.

Unitermos: hemangiopericitoma; tumor fibroso solitário; rim.

\section{REFERENCES}

1. AKBARNIA, B. A.; WIRTH, C. R.; COLMAN, N. Fibrosarcoma arising from chronic osteomyelitis. Case report and review of the literature. J Bone Joint Surg Am, v. 58, n. 1, p. 123 5, 1976.

2. BRUNNEMANN, R. B. et al. Extrapleural solitary fibrous tumor: a clinicopathologic study of 24 cases. Mod Pathol, v. 12, n. 11, p. 1034-42, 1999.

3. DOTAN, Z.A. et al. Solitary fibrous tumor presenting as perirenal mass associated with hypoglycemia.J Urol, v. 162, n. 6, p. 2087-8, 1999.

4. FUKUNAGA, M. et al. Extrapleural solitary fibrous tumor: a report of seven cases. Mod Pathol, v. 10, n. 5, p. 443-50, 1997.

5. HASEGAWA, T. et al. Extrathoracic solitary fibrous tumors: their histological variability and potentially aggressive behavior. Hum Pathol, v. 30, n. 12, p. 1464-73, 1999.

6. HASEGAWA, T. et al. Solitary fibrous tumor of the soft tissue. An immunohistochemical and ultrastructural study. Am J Clin Pathol, v. 106, n. 3, p. 325-31, 1996.

7. MENTZEL, T;; BAINBRIDGE, T. C.; KATENKAMP, D. Solitary fibrous tumour: clinicopathological, immunohistochemical, and ultrastructural analysis of 12 cases arising in soft tissues, nasal cavity and nasopharynx, urinary bladder and prostate. Virchows Arch, v. 430, n. 6, p. 445-53, 1997.
8. NIELSEN, G. P. et al. Solitary fibrous tumor of soft tissue: a report of 15 cases, including 5 malignant examples with light microscopic, immunohistochemical, and ultrastructural data. Mod Pathol, v. 10, n. 10, p. 1028-37, 1997.

9. STOUT, A. P.; MURRAY, M. R. Hemangiopericytoma: a vascular tumor featuring Zimmermann's pericytes. Ann Surg, v. 116, p. 26-33, 1942.

10. SUSTER, S. et al. Solitary fibrous tumors of soft tissue. A clinicopathologic and immunohistochemical study of 12 cases. Am J Surg Pathol, v. 19, n. 11, p. 1257-66, 1995.

11. TACCAGNI, G. et al. Solitary fibrous tumour of the thyroid: clinicopathological, immunohistochemical and ultrastructural study of three cases. Virchows Arch Pathol Anat Histopathol, v. 422, n. 6, p. 49197, 1993.

12. VALLAT-DECOUVELAERE, A. V.; DRY, S. M.; FLETCHER, C. D. Atypical and malignant solitary fibrous tumors in extrathoracic locations: evidence of their comparability to intra-thoracic tumors. Am J Surg Pathol, v. 22, n. 12, p. 1501-11, 1998.

13. WESTRA, W. H.; GRENKO, R. T.; EPSTEIN, J. Solitary fibrous tumor of the lower urogenital tract: a report of five cases involving the seminal vesicles, urinary bladder, and prostate. Hum Pathol, v. 31, n. 1, p. 63-8, 2000 . 